\title{
Distribution of the Harmful Bloom-Forming Cyanobacterium, Microcystis aeruginosa, in 88 Freshwater Environments across Japan
}

\author{
TAKafumi Kataoka $^{1 *}$, Kako Ohbayashi ${ }^{2}$, Yuki Kobayashi ${ }^{3}$, Hiroyuki TaKasu ${ }^{4}$, Shin-IChi NaKano ${ }^{5}$, Ryuji Kondo ${ }^{1}$, and \\ YOSHIKUNI HODOKI ${ }^{5}$ \\ ${ }^{1}$ Faculty of Marine Science and Technology, Fukui Prefectural University, 1-1 Gakuen-cho Obama, Fukui, 917-0003, Japan; \\ ${ }^{2}$ Graduate School of Arts and Sciences, The University of Tokyo, 3-8-1 Komaba, Meguro, Tokyo 153-8902, Japan; ${ }^{3}$ Faculty of \\ Health Sciences Yamaguchi University Graduate School of Medicine, Minamikogushi 1-1-1, Ube, Yamaguchi 755-8505 Japan; \\ ${ }^{4}$ Faculty of Environmental Science, Nagasaki University, 1-14 Bunkyo-machi, Nagasaki, 852-8521, Japan; and ${ }^{5}$ Center for \\ Ecological Research, Kyoto University, Otsu, Shiga, 520-2113, Japan
}

(Received August 15, 2019-Accepted December 7, 2019-Published online February 20, 2020)

Microcystis aeruginosa was quantitatively surveyed in 88 freshwater environments across Japan within 3 weeks in 2011. In order to clarify the distribution pattern of $M$. aeruginosa at the intra-species level, three major genotypes, which were defined by $16 \mathrm{~S}-23 \mathrm{~S}$ rRNA inter-transcribed-spacer (ITS) regions, were selectively detected using quantitative real-time PCR assays. Of the 68 sites at which the Microcystis intergenic-spacer region of the phycocyanin (IGS-PC) gene was detected, the $M$. aeruginosa morphotype-related genotype (MG1) dominated in 41 sites, followed by the non-toxic $M$. wesenbergii-related genotype (MG3). A correlation analysis showed that total nitrogen and phosphate positively correlated with the abundance of IGS-PC, which positively correlated with microcystin synthetase gene abundance. A redundancy analysis of genotype compositions showed that $\mathrm{pH}$ positively correlated with the dominance of MG3 and negatively correlated with MG1, i.e., both toxic and non-toxic genotypes. Our survey of Microcystis populations over a wide area revealed that MG1 is a dominant genotype in Japan.

Key words: Microcystis aeruginosa, 16S-23S ITS, qPCR, wide area distribution, genotype composition

Toxic cyanobacterial blooms are increasing public health and water quality management issues (Paerl, 2017). Massive blooms of Microcystis, one of the most pervasive bloomforming cyanobacteria worldwide, with the exception of Antarctica (Zurawell et al., 2005), cause serious damage to freshwater ecosystems and negatively impact the use of freshwater by human communities (Van Wichelen et al., 2016). Due to human activities, global warming, and eutrophication, the frequency, intensity, and geographic distribution of harmful algal blooms have increased over recent decades (Paerl and Paul, 2012).

The genus Microcystis has been characterized based on its morphological features under a microscope, namely, cell size, colony morphology, and the appearance of cells embedded in a mucilage matrix (Komárek and Anagnostidis, 1986; 1999). The most common populations appear to be $M$. aeruginosa, M. ichthyoblabe, M. novacekii, M. viridis, and M. wesenbergii (Komárek, 1991). However, molecular studies reported a high level of similarity among these morphologically diverse Microcystis strains, which share more than 97\% 16S rRNA gene sequence homology (Neilan et al., 1997; Otsuka et al., 1998), and more than 93\% intergenic-spacer region sequence homology in the phycocyanin-coding (IGS-PC) gene (Neilan et al., 1995; Bittencourt-Oliveira et al., 2001). Therefore, Microcystis strains have been unified under the species $M$. aeruginosa based on a bacteriological taxonomic criterion, namely, DNA-DNA hybridization of $>70 \%$ (Kondo et al., 2000;

\footnotetext{
* Corresponding author. E-mail address: kataoka@fpu.ac.jp;
} Tel: +81-770-52-6300; Fax: +81-770-52-6003.
Otsuka et al., 2001).

Molecular analyses have been applied to detect, quantify, and evaluate the diversity and/or abundance of Microcystis communities in natural environments. Intra-species genotyping has been performed for several genes, such as the 16S rRNA gene (Yoshida et al., 2005), IGS-PC (Neilan et al., 1995), and Microcystis 16S-23S rRNA internaltranscribed-spacer (16S-23S ITS) region sequences (Yoshida et al., 2008), and several genes have sufficient resolution to identify robust intra-specific genotypes. The quantification of gene copy numbers using real-time PCR (qPCR) is another genotyping method used in ecological studies. We developed qPCR methods to quantify intraspecies genotypes based on variations in the $16 \mathrm{~S}-23 \mathrm{~S}$ ITS sequence by referencing gene sequences derived from specimens worldwide (Kataoka et al., 2013). Furthermore, the gene cluster in microcystin synthetase $(m c y)$ has been used to detect toxin-producing and potentially toxic cyanobacteria genotypes (Baker et al., 2002).

Environmental studies demonstrated that $M$. aeruginosa is highly diverse at the intra-species level, not only among geographically distant ecosystems, but also during local bloom proliferation. Periodic studies of a local ecosystem showed temporal succession in the abundance and genotype variation of Microcystis (Yoshida et al., 2005; 2007). In contrast to temporal studies, few studies have focused on spatial distributions within the Microcystis community. Previous findings obtained on several aquatic environments suggested that the dynamics of Microcystis genotypes are affected by factors specific to each environment because the conditions that allow for the proliferation, community com- 
position formation, and mortality of Microcystis may involve various factors in the aquatic system. On a smaller scale as a comparison of two lakes, temperature and phosphate concentrations were identified as potential environmental factors affecting genotype dynamics, even though limnological parameters, including retention times and/or the stability of water, were also considered to affect genotype dynamics (Gagala et al., 2014; Li et al., 2014a). On the other hand, in a larger-scale study, in which a large number of aquatic systems were compared along strong environmental gradients (Marmen et al., 2016) and/or among various environments within an aquatic system, such as Lake Erie (Rinta-Kanto et al., 2009) and Lake Taihu (Li et al., 2014a), some key factors and Microcystis genotypes were suggested. When attempting to identify key factors affecting microbial compositions, a large sample size covering an environmental gradient is needed (Langenheder and Ragnarsson, 2007; Marmen et al., 2016).

To examine genotype distributions, we compared the Microcystis genotype composition among 88 aquatic systems across Japan, which is an island isolated from the continent. Three Microcystis genotypes, based on 16S-23S ITS sequence variations, and the gene copy number ratio of $m c y A$ to IGS-PC were analyzed using qPCR. In addition, the relationship between Microcystis genotype compositions and environmental parameters was investigated to identify the key factors involved in the formation of Microcystis genotypic variations.

\section{Materials and Methods}

\section{Sample collection and chemical analyses}

Sampling was conducted in 88 freshwater environments, including ponds, reservoirs, dams, and lakes, across a $750-\mathrm{km}$ area of Japan, between October 9th and 31st, 2011 (Fig. 1). Before sampling, in situ water temperature, conductivity, $\mathrm{pH}$, and turbidity were measured at the shoreline (Hodoki et al., 2013). Surface water samples were collected using a plastic bucket and stored in cold boxes for later analyses.

Two sets of 2-200-mL subsamples were filtered through precombusted (at $420^{\circ} \mathrm{C}$ for $3 \mathrm{~h}$ ) $\mathrm{GF} / \mathrm{F}$ filters (Whatman). The filters were wrapped in aluminum foil and stored at $-20^{\circ} \mathrm{C}$ until genomic DNA extraction and chlorophyll $a(\mathrm{Chl}-a)$ concentration measurements. The filtrates were also stored at $-20^{\circ} \mathrm{C}$ and used to analyze nutrients in the dissolved fraction. Nitrate $\left(\mathrm{NO}_{3}\right)$, nitrite $\left(\mathrm{NO}_{2}\right)$, and phosphate concentrations were examined colorimetrically using an AACS II Auto Analyzer (Bran+Luebbe, SPX), and total nitrogen (TN) and total phosphorus (TP) concentrations (including particle and dissolved fractions) were also measured colorimetrically after oxidation of the water sample with potassium persulfate (Pujo-pay and Raimbault, 1994). The ammonium concentration was measured fluorometrically (Holmes et al., 1999). Total inorganic carbon (TOC) concentrations were measured using a Shimadzu TOC-5000 analyzer (Shimadzu). Chl- $a$ was extracted with $10 \mathrm{~mL}$ of $\mathrm{N}, \mathrm{N}$ dimethylformamide (Suzuki and Ishimaru, 1990), and its concentration was measured using a spectrofluorophotometer (RF-5300. Shimadzu) following the method of Welschmeyer (1994).

\section{DNA extraction}

Genomic DNA was extracted from the whole GF/F filter using potassium xanthogenate-sodium dodecyl sulfate with a variation of the phenol/chloroform/isoamyl-alcohol (PCI) procedure (Tillett and Neilan, 2000) and homogenizing with pre-combusted glass beads (diameter $<106 \mu \mathrm{m})$ (Kataoka et al., 2013).

$q P C R$ of the gene fragment of IGS-PC, mcyA, and intra-specific genotypes within the 16S-23S ITS sequence

Three major genotype variations, defined by sequence variations within the 16S-23S ITS region, were selectively detected by realtime quantitative PCR (qPCR) using the three group-specific PCR primer sets, listed in Table S1: G3f/MITS-R for $M$. wesenbergiilike non-toxic group (MG3), MITS-F/G4r for M. viridis-like toxic group (MG4), and MITS-F/G1r for M. aeruginosa-like group (MG1) organisms, including toxic and non-toxic Microcystis strains. qPCR reactions for the three groups were performed as described by Kataoka et al. (2013), and qPCR for the IGS-PC and $m c y A$ genes according to the procedures described by Yoshida $e t$ al. (2007).

\section{Statistical analysis}

Variance in environmental variables and Microcystis-related var-
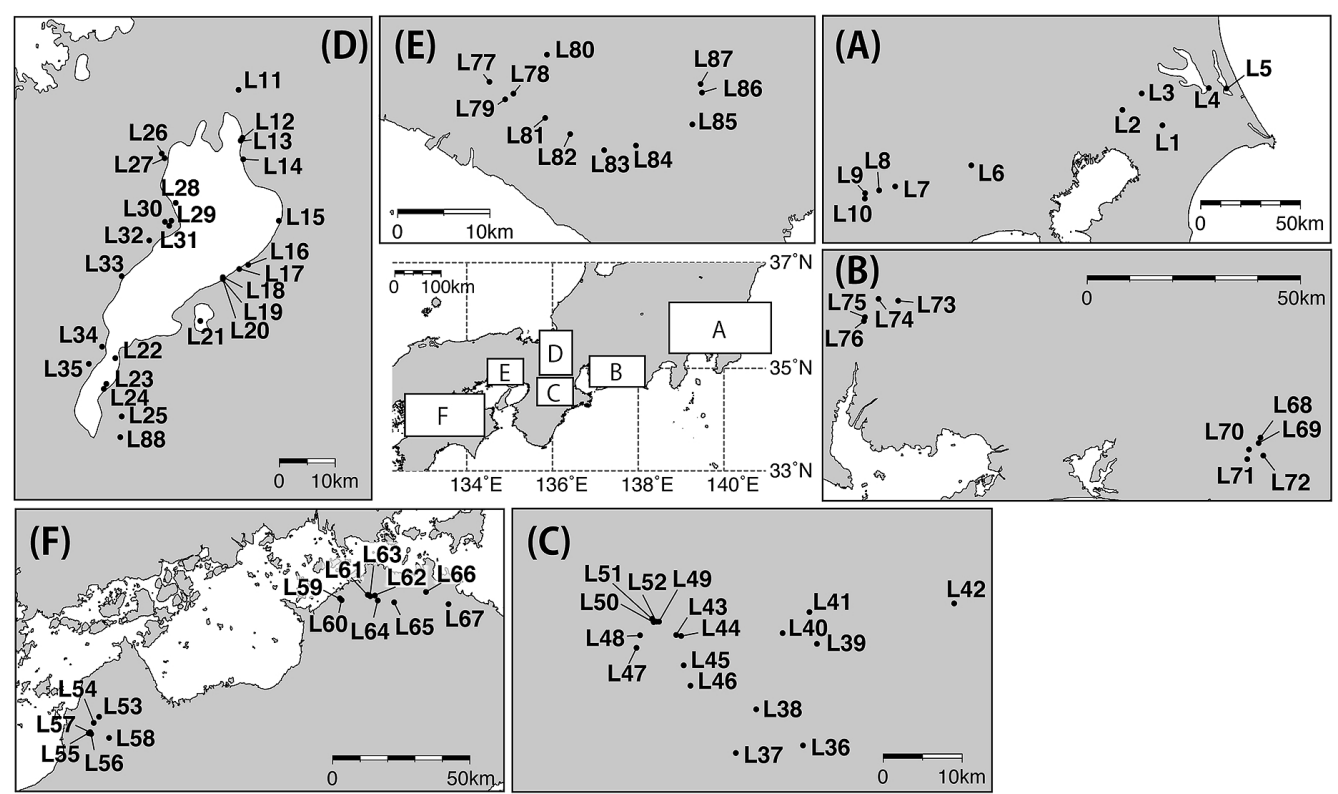

(C)

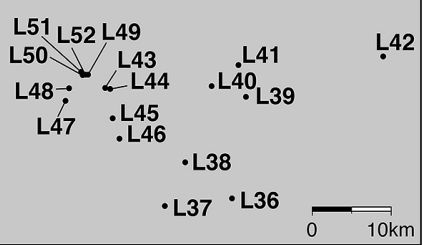

Fig. 1. Location of 88 lacustrine sites that were sampled for Microcystis between October 9th and 31st, 2011. 
iables, such as IGS-PC, which is related to Microcystis abundance, and the ratio of $m c y A$ to IGS-PC $(m c y A / \mathrm{PC})$, which is an index of the toxic genotype ratio of Microcystis, were visualized using the qqnorm function in the stats package (ver. 3.3.2) for software R. Variables showing a non-normal distribution were transformed by the square or fourth root or $\log 10$ conversion. The relative value, the difference from the minimum value, was applied to longitude and temperature; the square root to conductivity and TOC; the fourth root to turbidity, Chl- $a$, TN, TP, dissolved inorganic nitrogen (DIN), and $\mathrm{NO}_{3}$; and the logarithmic transformation to dissolved inorganic phosphorus (DIP), $\mathrm{NO}_{2}, \mathrm{NH}_{4}$, and PC. Multicollinearity among variables was then assessed by variance inflation factors (VIF) to remove variables showing VIF $>20$ in order for data on DIN and DIP/DIN to be eliminated from subsequent analyses because of their strong correlation with $\mathrm{NO}_{3}$ concentrations. Latitude was also eliminated for its strong correlation with longitude. The detection of Microcystis in a sample was performed based on the threshold cycle $(\mathrm{Ct})$ value of IGS-PC-based $\mathrm{qPCR}$ to remove samples showing $\mathrm{Ct}>30$. Outliers in $\mathrm{qPCR}$ data were identified by referring to a clustering analysis and ordination plot of non-metric multidimensional scaling (nMDS). In the remaining samples, the relative abundance of three major genotypes of the Microcystisspecific 16S-23S ITS (MITS) region of MG1, MG3, and MG4, was calculated. After conducting pairwise comparisons of dissimilarity based on the Bray-Curtis distance, significant clusters among sampling sites were tested by a similarity profile analysis (SIMPROF: clustering package) with $P<0.05$. The dissimilarity of the genotype composition among sampling sites was visualized, and the effects of environmental factors on the genotype composition were tested by a redundancy analysis (RDA: vegan package). To test the significance of constraints among the constructed RDA models, a non-parametric multivariate ANOVA test was conducted. The effects of environmental variables on the dissimilarity of the community composition were tested by a permutational multivariate analysis of variance (PERMANOVA: an adonis2 package), and the contribution of each environmental variable was estimated by alternatively eliminating each environmental variable (partial RDA). All statistical analyses were conducted using R software ver. 3.3.2 (http://cran.r-project.org).

\section{Results}

\section{Identification of outliers}

Water from a pond at site L81 showed extremely eutrophic conditions with $5,344 \mu \mathrm{g} \mathrm{L} \mathrm{L}^{-1}$ of Chl- $a, 206 \mu \mathrm{g} \mathrm{L} \mathrm{L}^{-1}$ of TOC, $77,390 \mu \mathrm{g} \mathrm{L}^{-1}$ of TN, and 7,130 $\mu \mathrm{g} \mathrm{L}^{-1}$ of TP, and the highest gene copy number for IGS-PC of $7.2 \times 10^{7}$ copies $\mathrm{mL}^{-1}$ and $m c y A$ of $1.0 \times 10^{7}$ copies $\mathrm{mL}^{-1}$, indicating a massive bloom of M. aeruginosa. Preliminary composition analyses, such as nMDS and cluster analyses, for the MITS genotypes (MG1, MG3, and MG4) showed that the Microcystis composition of a dam at site L36 markedly differed from that found in other sites. The MITS genotype composition of L36 was dominated by the MG4 genotype: $29.3 \%$ of the total MITS genotypes. Thus, sites L36 and L81 were excluded as outliers, which draw incorrect results.

\section{Environmental variables}

Seventy out of the 88 sampling sites shown in Fig. 1 showed the presence of Microcystis populations, which were widely distributed throughout Japan. Sixty-eight sites, after the removal of the two outliers described above, showed significantly higher water temperatures (ranging between 13.8 and $22.6^{\circ} \mathrm{C}$ ), $\mathrm{pH}$ values (ranging between 6.44 and
10.35), and TOC concentrations (ranging between 0.86 and $23 \mu \mathrm{g} \mathrm{L}^{-1}$ ) than the other 18 sites, at which no Microcystis populations were detected by IGS-PC-targeted qPCR (the Wilcoxon rank test: $P<0.01)$ (Fig. S1). Chl- $a$ concentrations ranged between 3.06 and $864 \mu \mathrm{gL}^{-1}$ and correlated with both TN (Pearson's correlation coefficient $R^{2}=0.76, P<0.01$ ) and TP (Pearson's correlation coefficient $R^{2}=0.77, P<0.01$ ).

\section{Microcystis population and toxic genotype}

The gene copy number of IGS-PC ranged between $1.2 \times 10^{2}$ and $3.7 \times 10^{7}$ copies $\mathrm{mL}^{-1}$ with an average of $9.4 \times 10^{5}$ copies $\mathrm{mL}^{-1}\left( \pm 4.5 \times 10^{6} \mathrm{SD}\right)$ (Fig. S1). The distribution of the IGS-PC gene copy number showed that $47(69.1 \%)$ sites contained less than $1.0 \times 10^{5}$ IGS-PC copies $\mathrm{mL}^{-1}$, whereas $12(17.6 \%)$ and $9(13.2 \%)$ sites showed a range of $1.0 \times 10^{5}$ to $1.0 \times 10^{6}$ copies $\mathrm{mL}^{-1}$ and more than $1.0 \times 10^{6}$ copies $\mathrm{mL}^{-1}$, respectively, with a median of $1.1 \times 10^{4}$ copies $\mathrm{mL}^{-1}$ (Fig. $\mathrm{S} 2 \mathrm{~A})$. The gene copy number of $m c y A$, which ranged between $1.4 \times 10^{1}$ and $3.6 \times 10^{6}$ copies $\mathrm{mL}^{-1}\left(1.1 \times 10^{5}\right.$ copies $\mathrm{mL}^{-1}$ on average, $\left.\pm 4.6 \times 10^{5} \mathrm{SD}\right)$, strongly correlated with the IGS-PC copy number $\left(R^{2}=0.91\right)$ (Fig. S2B). The percentage index of $m c y A / \mathrm{PC}$ was the highest $(50.01 \%)$ at one site. Twenty-six sites $(38.2 \%)$ were in the range of $<10 \%$, followed by $19,12,9$, and 1 sites in the range of 10-20, 20-30, $30-40$, and $40-50 \%$, respectively, with a median of $16.3 \%$.

\section{Correlation analysis of IGS-PC and mcyA/PC to environmental variables}

The pairwise correlation analysis revealed a correlation between the gene copy number of both IGS-PC and $m c y A / P C$ with environmental variables. The IGS-PC gene correlated with TN $(r=0.55)$, TP $(r=0.55)$, and TOC $(r=0.66)$, and IGS-PC strongly correlated with turbulence $(r=0.69)$ and Chl- $a(r=0.75)(P<0.05)$. However, mcyA/PC only showed a weak correlation with some variables $(r<0.4)$ (Table 1). The correlation patterns of IGS-PC were similar at sampling sites with a high IGS-PC gene copy number, $>1.0 \times 10^{5}$ copies $\mathrm{mL}^{-1}$ (21 sites), whereas no correlation was observed in samples with a lower IGS-PC gene copy number, $<1.0 \times 10^{5}$ copies $\mathrm{mL}^{-1}$ ( 47 sites) (Table S2).

\section{Composition of 16S-23S ITS genotypes and efficient environmental factors}

SIMPROF showed that the composition of Microcystis genotypes derived from 16S-23S ITS, i.e., MG1, MG3, and MG4, may be separated into five significant groups (SIMPROF, $P<0.05$; Fig. 2). In the largest SIMPROF group (41 sites), $94.7 \%$ of the MITS genotypes were MG1 and less than 2.3 and $5.3 \%$ were MG3 and MG4, respectively. Of the other distant SIMPROF-groups, S-group-2 was dominated by MG3, representing 25.7-71.7\%, and MG4, representing less than $2.4 \%$ of the MITS genotypes; S-group-3 was dominated by MG4, occupying $2.8-13.0 \%$, and MG3, representing $2.2-7.9 \%$ of the MITS genotypes. The remaining three SIMPROF-groups, S-group-4 to -6 , showed similar genotype patterns to each other, with MG1 being dominant, followed by MG3 and MG4.

The six groups also emerged in RDA, in which $40.0 \%$ of the total community variation was explained by environmental variables $P<0.05$ ) (Fig. 3 ). Of the total variation in 
Table 1. Correlation coefficients between environmental factors, ITS genotype relative abundance, Microcystis IGS-PC gene abundance, and the $m c y A / \mathrm{PC}$ ratio.

\begin{tabular}{|c|c|c|c|c|c|c|c|c|c|c|c|c|c|c|c|c|c|c|}
\hline & Lon & Tem & $\mathrm{pH}$ & Cond & Turb & Chl- $a$ & TOC & $\mathrm{TN}$ & $\mathrm{TP}$ & DIP & NO3 & $\mathrm{NO2}$ & NH4 & IGS-PC & mcyA/PC & MG1 & MG3 & MG4 \\
\hline Lon & 1 & & & & & & & & & & & & & & & & & \\
\hline Tem & $-0.27 * *$ & 1 & & & & & & & & & & & & & & & & \\
\hline $\mathrm{pH}$ & -0.16 & $0.36 * * *$ & 1 & & & & & & & & & & & & & & & \\
\hline Cond & $0.31 * *$ & $-0.25 * *$ & 0.01 & 1 & & & & & & & & & & & & & & \\
\hline Turb & -0.10 & 0.02 & 0.11 & 0.22 & 1 & & & & & & & & & & & & & \\
\hline Chl- $a$ & 0.00 & -0.02 & $0.27^{* *}$ & $0.33 * *$ & $0.83^{* * *}$ & 1 & & & & & & & & & & & & \\
\hline TOC & -0.18 & 0.12 & $0.28 * *$ & 0.23 & $0.77 * * *$ & $0.82 * * *$ & 1 & & & & & & & & & & & \\
\hline $\mathrm{TN}$ & -0.06 & -0.01 & 0.13 & $0.29 * *$ & $0.76 * * *$ & $0.75^{* * *}$ & $0.7^{* * *}$ & 1 & & & & & & & & & & \\
\hline TP & -0.01 & 0.02 & 0.07 & $0.29 * *$ & $0.77 * * *$ & $0.78^{* * *}$ & $0.79^{* * *}$ & $0.78^{* * *}$ & 1 & & & & & & & & & \\
\hline DIP & 0.06 & -0.02 & -0.17 & 0.16 & 0.17 & 0.09 & 0.17 & $0.3^{* *}$ & $0.57^{* * *}$ & 1 & & & & & & & & \\
\hline NO3 & 0.21 & -0.26 & $-0.33^{* *}$ & 0.17 & -0.28 & $-0.35 * * *$ & $-0.45^{* * *}$ & 0.12 & -0.19 & $0.27^{* *}$ & 1 & & & & & & & \\
\hline $\mathrm{NO} 2$ & $0.28 * *$ & -0.35 & $-0.31 * *$ & $0.32 * *$ & -0.09 & -0.19 & $-0.33^{* *}$ & 0.17 & -0.04 & $0.34^{* * *}$ & $0.87^{* * *}$ & 1 & & & & & & \\
\hline $\mathrm{NH} 4$ & 0.10 & -0.36 & $-0.34 * *$ & 0.18 & -0.05 & -0.13 & -0.21 & 0.09 & 0.00 & 0.19 & $0.5^{* * *}$ & $0.62 * * *$ & 1 & & & & & \\
\hline IGS-PC & -0.22 & 0.23 & $0.34^{* * *}$ & 0.12 & $0.69 * * *$ & $0.75^{* * *}$ & $0.66^{* * *}$ & $0.55^{* * *}$ & $0.55^{* * *}$ & -0.01 & $-0.4^{* * *}$ & $-0.29 * *$ & -0.12 & 1 & & & & \\
\hline mcyA/PC & -0.19 & -0.02 & -0.09 & $-0.41^{* * *}$ & -0.18 & $-0.4^{* * *}$ & -0.24 & $-0.27^{* *}$ & $-0.31 * *$ & -0.07 & 0.04 & 0.07 & 0.06 & $-0.3^{* *}$ & 1 & & & \\
\hline MG1 & 0.07 & -0.02 & $-0.29 * *$ & 0.00 & 0.09 & -0.10 & -0.08 & -0.08 & -0.02 & 0.04 & -0.04 & 0.02 & 0.03 & 0.03 & $0.32 * *$ & 1 & & \\
\hline MG3 & -0.07 & 0.02 & $0.31^{* *}$ & 0.01 & -0.06 & 0.13 & 0.09 & 0.12 & 0.04 & -0.06 & 0.05 & -0.01 & -0.04 & -0.03 & $-0.33^{* *}$ & $-0.98 * * *$ & 1 & \\
\hline MG4 & 0.00 & -0.03 & -0.07 & -0.08 & -0.14 & -0.11 & -0.08 & -0.18 & -0.10 & 0.09 & -0.07 & -0.06 & 0.05 & -0.03 & 0.02 & -0.19 & 0.00 & 1 \\
\hline
\end{tabular}

** $P<0.05 ; * * * P<0.01$

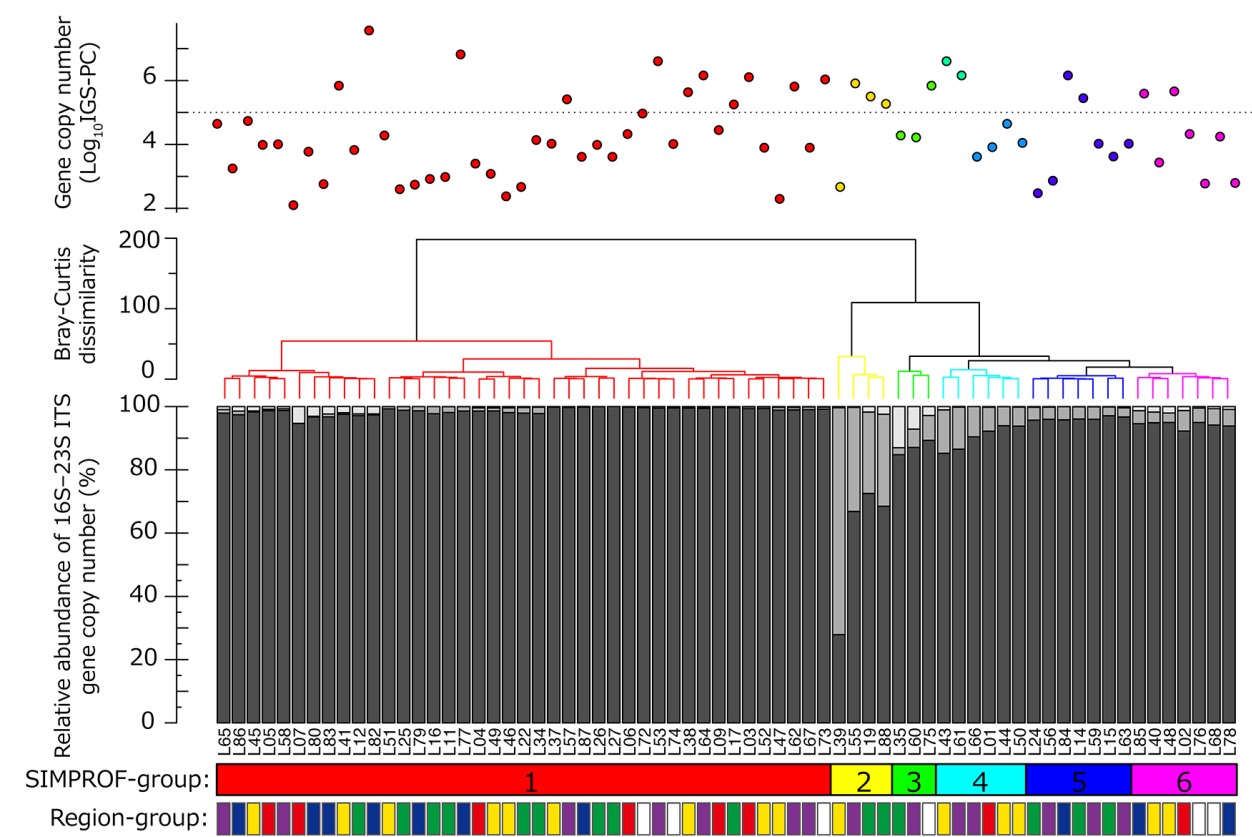

Fig. 2. Microcystis genotypic composition described by the relative abundance of three genotypes, MG1, MG3, and MG4 (bottom). The composition of each site is grouped according to the SIMPROF analysis based on the Bray-Curtis distance $(P<0.05)$ (middle). The abundance of the IGS-PC gene copy number is shown (top). Dark gray, pale gray, and white in the bottom panel indicate the Microcystis genotypes of MG1, MG3, and MG4, respectively. The color charts below the bottom panel show the groups as a result of the SIMPROF analysis (S-group) and the geographical groups as described in Fig. 1. Red, white, yellow, green, blue, and purple correspond to the regions A, B, C, D, E, and F, respectively, in Fig. 1. The dotted line in the top panel shows the threshold IGS-PC gene copy abundance between high and low abundance communities $\left(10^{5}\right.$ copies $\left.\mathrm{mL}^{-1}\right)$.

the MITS community composition, $37.5 \%$ was explained along the RDA1 axis, whereas only $0.21 \%$ was along the RDA2 axis. S-group-1, S-group-2, and S-group-3 were distantly located along the RDA1 axis, and even S-group-3 was scattered along the RDA2 axis. In contrast, the other SIMPROF-groups, S-group-4 to -6, were dispersed less in the RDA plot. $\mathrm{pH}, \mathrm{Chl}-a$, and $m c y A / \mathrm{PC}$ significantly affected the MITS genotype composition (PERMANOVA, $P<0.05)$. Partial RDA showed that $m c y A / \mathrm{PC}$ and $\mathrm{pH}$ strongly contributed to total variance, representing 10.7 and
$8.1 \%$ of the total variance, respectively. Of the significant environmental variables identified, $\mathrm{pH}$ was positively affected in S-group-2, which was dominated by the MITS genotype MG3, and $m c y A / \mathrm{PC}$ was positively affected in Sgroup-1, which was dominated by MG1. The correlation analysis also showed that $\mathrm{pH}$ positively correlated with MG3 $(r=0.31, P<0.05)$ and negatively correlated with MG1 $(r=0.29, P<0.05)$ (Table 1). Chl- $a$ concentrations, which slightly contributed to the MITS genotype composition (1.9\% of total variance), were affected in S-group- 4 to -6 . 


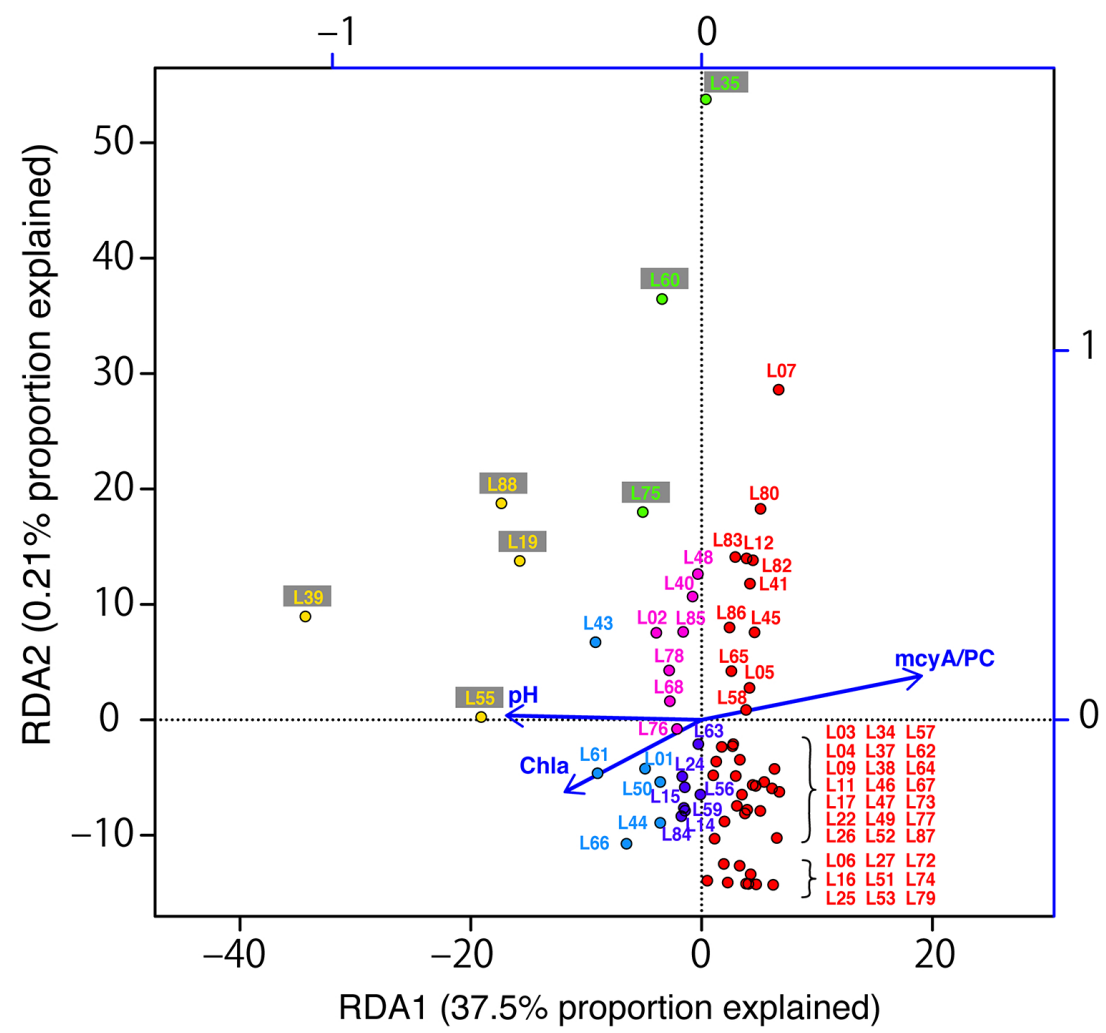

Fig. 3. RDA analysis based on Microcystis genotypic composition. Color corresponds to the grouping as a result of the SIMPROF analysis shown in Fig. 2. Chl- $a$ and $m c y A / \mathrm{PC}$ indicate chlorophyll $a$ concentrations and the ratio of $m c y A$ to the IGS-PC gene copy number, respectively. The length and direction of the arrows indicate the contribution of environmental variables.

\section{Discussion}

\section{Composition and abundance of 16S-23S ITS genotypes}

The three genotype groups of the 16S-23S ITS region, corresponding to MG1, MG3, and MG4, detected by the full-length sequencing analysis of the 16S-23S ITS region, were dominant in Microcystis obtained from 12 lacustrine sites in western Japan (Ohbayashi et al., 2013). This agreement between culture-dependent and culture-independent analyses supports the accurate detection of Microcystis genotypes in the present study. The dominance of MG1 was observed irrespective of the bloom scale, which was estimated by IGS-PC gene abundance (top panel in Fig. 2), but weakly correlated with $m c y A / \mathrm{PC}$ (Table 1). This suggests that the MG1 genotype is widely distributed across Japan, irrespective of the bloom phase because our samples may have included the early, middle, and late phases of Microcystis bloom. These results correspond to previous findings showing that the 16S-23S ITS genotypes were highly heterogeneous, and some were globally distributed (Janse et al., 2003; 2004). Moreover, the primers MG1 were designed to detect various Microcystis phenotypes, including microcystin-producing and non-microcystinproducing strains, and several morphospecies, including $M$. aeruginosa, M. flos-aquae, and M. ichthyoblabe, which have been detected worldwide (Kataoka et al., 2013). Although the genotype variation of Microcystis, assessed by the 16S-23S ITS region-based denaturing gradient gel electrophoresis analysis, was relatively low in several freshwa- ter environments (Kardinaal et al., 2007), a recent comparison of a large number of sites revealed that the genetic diversity of the 16S-23S ITS region was irrespective of geographic distance (Ohbayashi et al., 2013). Temporal surveys have shown that the genotypic compositions of Microcystis markedly changed from before to after bloom formation (Yoshida et al., 2005; Kardinaal et al., 2007). The sites at which the MG1 genotype dominated require more intense investigations using temporal surveys and a focus on the toxic genotypes within MG1. Furthermore, the diversity within MG1 needs to be examined in more detail using a whole-genome analysis (Yamaguchi et al., 2018).

MG3 was the second most dominant genotype and was also distributed across sampling sites, irrespective of IGSPC gene abundance (Fig. 2). This genotype includes only a single morphospecies of $M$. wesenbergii (Kataoka et al., 2013), which does not produce microcystins (Kurmayer et al., 2002; Xu et al., 2008). Of the 68 sampling sites at which the Microcystis IGS-PC gene was detected, 27 (40\%) contained MG3, even at sites at which the relative abundance of Microcystis was less than 33\% (L55). However, at the highest relative MG3 abundance of $72 \%$ (site L39), there was low IGS-PC gene abundance (approximately 4,000 IGS-PC gene copies $\mathrm{mL}^{-1}$ ). The corresponding morphospecies of $M$. wesenbergii are globally distributed, but are less frequently found at high concentrations than M. aeruginosa. In other words, cyanobacteria blooms are less frequently dominated by $M$. wesenbergii in Europe (Via-Ordorika et al., 2004). However, this morphospecies has been reported to regularly form massive blooms in aquatic ecosystems in China (Xu et 
al., 2008). Imai et al. (2009) reported that morphospecies of $M$. wesenbergii co-existed with $M$. aeruginosa in Japan and occupied between 10 and $80 \%$ of the phytoplankton composition throughout the year in a dam lake. The distribution pattern of the genotype MG3 strongly agrees with the distribution pattern of $M$. wesenbergii detected by both molecular and microscopy analyses. Thus, the present results indicate that the distribution of the MG3 genotype is not limited by distance, but is rarely a highly abundant member of the phytoplankton community in Japan. However, based on biomass, the large cell volume and thick mucilaginous sheath of $M$. wesenbergii indicate that these phytoplankton (Komárek, 1958; Imai et al., 2009) are sufficiently common to be very problematic.

The genotype MG4, which exclusively included microcystin-producing toxic morphotypes of $M$. viridis, rarely dominated sites in the present study, indicating their limited distribution or that they are limited by the overwhelming abundance of the other genotypes of Microcystis or other phytoplankton. The absence of any correlation between MG4 abundance and $m c y A / \mathrm{PC}$ (Table 1) may be attributed to insufficient sampling efforts. To expand our knowledge on how the Microcystis community composition is formed, further studies on environmental factors and/or competition mechanisms among these genotypes are needed.

\section{Toxic genotype abundance and environmental factors}

The pairwise correlation analysis was used to examine relationships between environmental factors and Microcystis abundance and between environmental factors and $m c y A / P C$ (Table 1 and S2). Microcystis abundance, estimated by the IGS-PC gene copy number, positively correlated with TN and TP $(P<0.05)$ when total samples (68 samples) and highIGS-PC samples $\left(21\right.$ sites: $1.0 \times 10^{5}$ copies $\left.\mathrm{mL}^{-1}>\mathrm{PC}\right)$ were both analyzed. Non-nitrogen-fixing Microcystis depend on inorganic nutrient availability (Orr and Jones, 1998; Gobler et al., 2016). On the other hand, low-nutrient conditions, which were defined as concentrations of less than $400 \mu \mathrm{g} \mathrm{L}^{-1}$ for TN and/or $20 \mu \mathrm{g} \mathrm{L}^{-1}$ for TP (Fujimoto et al., 1997), were observed at 18 sites, and these sites also showed low Microcystis abundance $\left(2.0 \times 10^{2}\right.$ to $1.8 \times 10^{4}$ copies $\mathrm{mL}^{-1}$ of the IGS-PC gene) or levels below the detection limit. Although TN and/or TP have been shown to correlate with toxic cyanobacteria abundance (Vézie et al., 2002; Davis et al., 2009; Li et al., 2014b), it is important to note that Microcystis itself contributes to TN, TP, and TOC concentrations. Although the present results showed no correlation between the index of $m c y A / \mathrm{PC}$ and environmental factors, the gene abundance of $m c y A$ and IGS-PC positively correlated in a log-log scale comparison $\left(R^{2}=0.91\right.$, Fig. $\mathrm{S} 2 \mathrm{~B})$. Regarding other environmental factors, genotype composition was affected by $\mathrm{pH}$, and the proportion of the MG3 genotype and $\mathrm{pH}$ positively correlated (Table 1 and Fig. 3). To date, culture studies have shown that Microcystis preferentially grow in neutral to weak alkaline conditions, i.e., $\mathrm{pH}>6.5$ (Wang et al., 2011). Of our 88 samples, 68 sampling sites at which the IGS-PC gene was detected had a $\mathrm{pH}>7.0$, excluding site $\mathrm{L} 27$ at which we detected a $\mathrm{pH}$ of 6.44 and low IGS-PC gene abundance. Therefore, a neutral to alkaline $\mathrm{pH}$ environment appears to be a significant factor for the maintenance of Microcystis populations. More specifically, Yang et al. (2018) showed that a $\mathrm{pH}$ in the range of 7-8 was optimum for $M$. aeruginosa strain 7806, which belongs to MG1 in our genotype grouping, and conditions under $\mathrm{pH} 6$ and over $\mathrm{pH} 9$ were hostile to growth. The present results also showed that $\mathrm{pH} 7-8$ was optimum for Microcystis populations because the majority of MG1dominated populations $(65.9 \%, 27 / 41)$, which were designated as S-group-1, were derived from sites with a $\mathrm{pH}$ in this range. In addition, IGS-PC was detected in only four sites at which $\mathrm{pH}$ was $>9$, with the maximum $\mathrm{pH}$ value being 9.68. However, for MG3-abundant populations, designated as S-group-2 and S-group-4 to -6 , the IGS-PC gene was detected up to $\mathrm{pH}$ 10.4. Since $\mathrm{pH}$ increases as Microcystis blooms grow because of $\mathrm{CO}_{2}$ consumption by photosynthesis (Paerl and Ustach, 1982; Krausfeldt et al., 2019), dominant morphotypes in the late bloom phase may be adapted to high pH. $M$. aeruginosa and $M$. wesenbergii formed large colonies in the late bloom phase between August and October in Lake Taihu (Li et al., 2016; Xiao et al., 2018). Thus, MG3 may survive at the late bloom phase. The predominance of Microcystis under high $\mathrm{pH}$ conditions has been reported in the natural phytoplankton community (Shapiro, 1997) and in experimental co-cultures, including Microcystis and a chlorophyta (Nakano et al., 2003). Shapiro (1997) showed that Microcystis exhibited relatively low photosynthesis activity under high $\mathrm{pH}$ conditions, suggesting that under these conditions, Microcystis enters a state of maintenance with low levels of reproduction. This tolerance to a high $\mathrm{pH}$ may be why the species dominates over other phytoplankton (Nakano et al., 2003). The present results indicate that $\mathrm{pH}$ is an important factor for community compositional differences at the intra-species genotype level. Moreover, $\mathrm{pH}$ positively correlated with MG3 and negatively correlated with MG1 relative abundance, supporting a previous study indicating a negative correlation between $m c y D$ abundance and $\mathrm{pH}$ (Rinta-Kanto et al., 2009). $\mathrm{pH}$ also appears to be one of the driving forces behind the formation of harmful and/or non-harmful Microcystis blooms.

\section{Methodological considerations}

This wide area, short-term survey of Microcystis populations revealed that one genotype, MG1, dominated the most in lacustrine environments in Japan. We also succeeded in identifying some of the environmental factors affecting Microcystis genotype composition, e.g., $\mathrm{pH}$, and those affecting Microcystis abundance, e.g., TN and TP. However, it is important to note that in our snapshot survey, difficulties may be associated with completely elucidating Microcystis population dynamics because cyanobacteria blooms are seasonal events, and cyanobacteria populations respond to temporary environmental variations (Yoshida et al., 2007; Rinta-Kanto et al., 2009). For example, Yoshida et al. (2007) found a positive correlation between the $m c y A / \mathrm{PC}$ ratio and $\mathrm{NO}_{3}$, whereas no correlation was found in the present study. Furthermore, the composition of the three genotypes defined by the $16 \mathrm{~S}-23 \mathrm{~S}$ ITS region did not reveal any relationships between genotype compositions and 
aquatic environment categories (Table S3; e.g., dam, pond, lake, and marsh) or geographic distances (Fig. S3) because we analyzed genotype abundance rather than genotype composition. Temporal and wide area surveys targeting genotypic diversity (e.g., metagenome analyses and/or wholegenome types) are both needed to obtain further insights into Microcystis population dynamics.

\section{Acknowledgements}

This study was supported by the Environment Research and Technology Development Fund (D-0905) from the Ministry of the Environment, Japan.

\section{References}

Baker, J.A., Entsch, B., Neilan, B.A., and McKay, D.B. (2002) Monitoring changing toxigenicity of a cyanobacterial bloom by molecular methods. Appl Environ Microbiol 68: 6070-6076.

Bittencourt-Oliveira, M.d.C., de Oliveira, M.C., and Bolch, C.J.S. (2001) Genetic variability of Brazilian strains of the Microcystis aeruginosa complex (Cyanobacteria/Cyanophyceae) using the phycocyanin intergenic spacer and flanking regions $(c p c \mathrm{BA}) . J$ Phycol 37: 810818.

Davis, T.W., Berry, D.L., Boyer, G.L., and Gobler, C.J. (2009) The effects of temperature and nutrients on the growth and dynamics of toxic and non-toxic strains of Microcystis during cyanobacteria blooms. Harmful Algae 8: 715-725.

Fujimoto, N., Sudo, R., Sugiura, N., and Inamori, Y. (1997) Nutrientlimited growth of Microcystis aeruginosa and Phormidium tenue and competition under various $\mathrm{N}: \mathrm{P}$ supply ratios and temperatures. Limnol Oceanogr 42: 250-256.

Gagala, I., Izydorczyk, K., Jurczak, T., Pawelczyk, J., Dziadek, J., Wojtal-Frankiewicz, A. et al. (2014) Role of environmental factors and toxic genotypes in the regulation of microcystins-producing cyanobacterial blooms. Microb Ecol 67: 465-479.

Gobler, C.J., Burkholder, J.M., Davis, T.W., Harke, M.J., Johengen, T., Stow, C.A., and Van de Waal, D.B. (2016) The dual role of nitrogen supply in controlling the growth and toxicity of cyanobacterial blooms. Harmful Algae 54: 87-97.

Hodoki, Y., Ohbayashi, K., Kobayashi, Y., Takasu, H., Okuda, N., and Nakano, S. (2013) Anatoxin-a-producing Raphidiopsis mediterranea Skuja var. grandis Hill is one ecotype of non-heterocytous Cuspidothrix issatschenkoi (Usačev) Rajaniemi et al. in Japanese lakes. Harmful Algae 21-22: 44-53.

Holmes, R.M., Aminot, A., Kérouel, R., Hooker, B.A., and Peterson, B.J. (1999) A simple and precise method for measuring ammonium in marine and freshwater ecosystems. Can J Fish Aquat Sci 56: 18011808.

Imai, H., Chang, K.H., Kusaba, M., and Nakano, S. (2009) Temperaturedependent dominance of Microcystis (Cyanophyceae) species: $M$. aeruginosa and M. wesenbergii. J Plankton Res 31: 171-178.

Janse, I., Meima, M., Kardinaal, W.E.A., and Zwart, G. (2003) Highresolution differentiation of cyanobacteria by using rRNA-internal transcribed spacer denaturing gradient gel electrophoresis. Appl Environ Microbiol 69: 6634-6643

Janse, I., Kardinaal, W.E.A., Meima, M., Fastner, J., Visser, P.M., and Zwart, G. (2004) Toxic and nontoxic microcystis colonies in natural populations can be differentiated on the basis of rRNA gene internal transcribed spacer diversity. Appl Environ Microbiol 70: 3979-3987.

Kardinaal, W.E.A., Janse, I., Kamst-van Agterveld, M., Meima, M., Snoek, J., Mur, L.R. et al. (2007) Microcystis genotype succession in relation to microcystin concentrations in freshwater lakes. Aquat Microb Ecol 48: 1-12.

Kataoka, T., Homma, T., Nakano, S., Hodoki, Y., Ohbayashi, K., and Kondo, R. (2013) PCR primers for selective detection of intraspecies variations in the bloom-forming cyanobacterium, Microcystis. Harmful Algae 23: 46-54.

Komárek, J. (1958) Die taxonomische revision der planktischen blaualgen der Tschechoslowakei. In Algologische Studien. Weinheim: Verlag Der Tschechoslowakischen Akademie Der Wissenschaften, pp. 10-206.
Komárek, J., and Anagnostidis, K. (1986) Modern approach to the classification system of cyanophytes 2. chroococcales. Algol Stud 73: $157-226$

Komárek, J. (1991) A review of water-bloom forming Microcystis species, with regard to populations from Japan. Algol Stud 64: 115127.

Komárek, J., and Anagnostidis, K. (1999) Cyanoprokaryota 1. Teil: Chroococcales. Süßwasserflora von Mitteleuropa 19/1. Heidelberg: Spektrum Akademischer Verlag.

Kondo, R., Yoshida, T., Yuki, Y., and Hiroishi, S. (2000) DNA-DNA reassociation among a bloom-forming cyanobacterial genus. Microcystis. Int J Syst Evol Microbiol 50: 767-770.

Krausfeldt, L.E., Farmer, A.T., Castro Gonzalez, H.F., Zepernick, B.N., Campagna, S.R., and Wilhelm, S.W. (2019) Urea is both a carbon and nitrogen source for Microcystis aeruginosa: tracking 13C incorporation at bloom pH conditions. Front Microbiol 10: 1064.

Kurmayer, R., Dittmann, E., Fastner, J., and Chorus, I. (2002) Diversity of microcystin genes within a population of the toxic cyanobacterium Microcystis spp. in Lake Wannsee (Berlin, Germany). Microb Ecol 43: 107-118.

Langenheder, S., and Ragnarsson, H. (2007) The role of environmental and spatial factors for the composition of aquatic bacterial communities. Ecology 88: 2154-2161.

Li, D., Gu, A.Z., and He, M. (2014a) Quantification and genetic diversity of total and microcystin-producing Microcystis during blooming season in Tai and Yang-cheng lakes, China. J Appl Microbiol 116: $1482-1494$.

Li, D.M., Yu, Y., Yang, Z., Kong, F.X., Zhang, T.Q., and Tang, S.K. (2014b) The dynamics of toxic and nontoxic Microcystis during bloom in the large shallow lake, Lake Taihu, China. Environ Monit Assess 186: 3053-3062.

Li, M., Zhu, W., Guo, L., Hu, J., Chen, H., and Xiao, M. (2016) To increase size or decrease density? Different Microcystis species has different choice to form blooms. Sci Rep 6: 37056.

Marmen, S., Aharonovich, D., Grossowicz, M., Blank, L., Yacobi, Y.Z., and Sher, D.J. (2016) Distribution and habitat specificity of potentially-toxic Microcystis across climate, land, and water use gradients. Front Microbiol 7: 271.

Nakano, S.-i., Murabe, A., Tsujimura, S., Hayakawa, K., Nakajima, T., Kumagai, M., et al. (2003) Dominance of Microcystis with special reference to carbon availability in lake water. Microbes Environ 18: $38-42$.

Neilan, B.A., Jacobs, D., and Goodman, A.E. (1995) Genetic diversity and phylogeny of toxic cyanobacteria determined by DNA polymorphisms within the phycocyanin locus. Appl Environ Microbiol 61: 3875-3883.

Neilan, B.A., Jacobs, D., DelDot, T., Blackall, L.L., Hawkins, P.R., Cox, P.T., and Goodman, A.E. (1997) rRNA sequences and evolutionary relationships among toxic and nontoxic cyanobacteria of the genus Microcystis. Int J Syst Bacteriol 47: 693-697.

Ohbayashi, K., Hodoki, Y., Kobayashi, Y., Okuda, N., and Nakano, S. (2013) Genotypic composition and the relationship between genotypic composition and geographical proximity of the cyanobacterium Microcystis aeruginosa in western Japan. Can J Microbiol 59: 266-272.

Orr, P.T., and Jones, G.J. (1998) Relationship between microcystin production and cell division rates in nitrogen-limited Microcystis aeruginosa cultures. Limnol Oceanogr 43: 1604-1614.

Otsuka, S., Suda, S., Li, R.H., Watanabe, M., Oyaizu, H., Matsumoto, S., and Watanabe, M.M. (1998) 16S rDNA sequences and phylogenetic analyses of Microcystis strains with and without phycoerythrin. FEMS Microbiol Lett 164: 119-124.

Otsuka, S., Suda, S., Shibata, S., Oyaizu, H., Matsumoto, S., and Watanabe, M.M. (2001) A proposal for the unification of five species of the cyanobacterial genus Microcystis Kützing ex Lemmermann 1907 under the Rules of the Bacteriological Code. Int J Syst Evol Microbiol 51: 873-879.

Paerl, H.W., and Ustach, J.F. (1982) Blue-green algal scums: An explanation for their occurrence during freshwater blooms1. Limnol Oceanogr 27: 212-217.

Paerl, H.W., and Paul, V.J. (2012) Climate change: Links to global expansion of harmful cyanobacteria. Water Res 46: 1349-1363.

Paerl, H.W. (2017) Controlling harmful cyanobacterial blooms in a climatically more extreme world: management options and research needs. J Plankton Res 39: 763-771. 
Pujo-pay, M., and Raimbault, P. (1994) Improvement of the wetoxidation procedure for simultaneous determination of particulate organic nitrogen and phosphorus collected on filters. Mar Ecol Prog Ser 105: 203-207.

Rinta-Kanto, J.M., Konopko, E.A., DeBruyn, J.M., Bourbonniere, R.A., Boyer, G.L., and Wilhelm, S.W. (2009) Lake Erie Microcystis: Relationship between microcystin production, dynamics of genotypes and environmental parameters in a large lake. Harmful Algae 8: 665-673.

Shapiro, J. (1997) The role of carbon dioxide in the initiation and maintenance of blue-green dominance in lakes. Freshw Biol 37: 307-323.

Suzuki, R., and Ishimaru, T. (1990) An improved method for the determination of phytoplankton chlorophyll using $\mathrm{N}, \mathrm{N}-$ dimethylformamide. J Oceanogr 46: 190-194.

Tillett, D., and Neilan, B.A. (2000) Xanthogenate nucleic acid isolation from cultured and environmental cyanobacteria. $J$ Phycol 36: 251258.

Van Wichelen, J., Vanormelingen, P., Codd, G.A., and Vyverman, W. (2016) The common bloom-forming cyanobacterium Microcystis is prone to a wide array of microbial antagonists. Harmful Algae 55: 97-111.

Vézie, C., Rapala, J., Vaitomaa, J., Seitsonen, J., and Sivonen, K. (2002) Effect of nitrogen and phosphorus on growth of toxic and nontoxic Microcystis strains and on intracellular microcystin concentrations. Microb Ecol 43: 443-454.

Via-Ordorika, L., Fastner, J., Kurmayer, R., Hisbergues, M., Dittmann, E., Komárek, J., et al. (2004) Distribution of microcystin-producing and non-microcystin-producing Microcystis sp in European freshwater bodies: Detection of microcystins and microcystin genes in individual colonies. Syst Appl Microbiol 27: 592-602.

Wang, X., Hao, C.B., Zhang, F., Feng, C.P., and Yang, Y.N. (2011) Inhibition of the growth of two blue-green algae species (Microsystis aruginosa and Anabaena spiroides) by acidification treatments using carbon dioxide. Bioresour Technol 102: 5742-5748.
Welschmeyer, N.A. (1994) Fluorometric analysis of chlorophyll $a$ in the presence of chlorophyll $b$ and pheopigments. Limnol Oceanogr 39: 1985-1992.

Xiao, M., Li, M., and Reynolds, C.S. (2018) Colony formation in the cyanobacterium Microcystis. Biol Rev Cambridge Philos Soc 93: 1399-1420.

Xu, Y., Wu, Z.X., Yu, B.S., Peng, X., Yu, G.L., Wei, Z.H., et al. (2008) Non-microcystin producing Microcystis wesenbergii (Komárek) Komárek (Cyanobacteria) representing a main waterbloom-forming species in Chinese waters. Environ Pollut 156: 162-167.

Yamaguchi, H., Suzuki, S., and Kawachi, M. (2018) Draft genome sequence of Microcystis aeruginosa NIES-87, a bloom-forming cyanobacterium from Lake Kasumigaura, Japan. Genome Announc 6: e01596-17.

Yang, J.W., Tang, H.X., Zhang, X.X., Zhu, X.X., Huang, Y., and Yang, Z. (2018) High temperature and $\mathrm{pH}$ favor Microcystis aeruginosa to outcompete Scenedesmus obliquus. Environ Sci Pollut Res 25: 47944802.

Yoshida, M., Yoshida, T., Takashima, Y., Kondo, R., and Hiroishi, S. (2005) Genetic diversity of the toxic cyanobacterium Microcystis in Lake Mikata. Environ Toxicol 20: 229-234.

Yoshida, M., Yoshida, T., Takashima, Y., Hosoda, N., and Hiroishi, S. (2007) Dynamics of microcystin-producing and non-microcystinproducing Microcystis populations is correlated with nitrate concentration in a Japanese lake. FEMS Microbiol Lett 266: 49-53.

Yoshida, M., Yoshida, T., Satomi, M., Takashima, Y., Hosoda, N., and Hiroishi, S. (2008) Intra-specific phenotypic and genotypic variation in toxic cyanobacterial Microcystis strains. J Appl Microbiol 105: 407-415.

Zurawell, R.W., Chen, H.R., Burke, J.M., and Prepas, E.E. (2005) Hepatotoxic cyanobacteria: A review of the biological importance of microcystins in freshwater environments. $J$ Toxicol Environ Health, Part B 8: 1-37. 